\title{
Risk of incident or recurrent malignancies among patients with rheumatoid arthritis exposed to biologic therapy in the German biologics register RABBIT
}

Anja Strangfeld ${ }^{* 1}$, Franka Hierse1, Rolf Rau2 ${ }^{2}$ Gerd-Ruediger Burmester ${ }^{3}$, Brigitte Krummel-Lorenz ${ }^{4}$, Winfried Demary ${ }^{5}$, Joachim Listing ${ }^{1}$ and Angela Zink1,3

\begin{abstract}
Introduction: We used the data of the German biologics register RABBIT, a nationwide prospective cohort study, to investigate the risk of new or recurrent malignancy in patients with rheumatoid arthritis (RA) receiving biologics compared to conventional disease modifying anti-rheumatic drugs (DMARDs).

Methods: The analysis was based on patients with RA enrolled in RABBIT at the start of a biologic or conventional DMARD therapy between 01 May 2001 and 31 December 2006. Incidences of first or recurrent malignancies were analysed separately. A nested case-control design was used to investigate the risk of developing a first malignancy. Matching criteria were: age, gender, follow-up time, disease activity score based on 28 joint counts (DAS28) at study entry, smoking status, and selected chronic co-morbid conditions (obstructive or other lung disease, kidney, liver or gastrointestinal disease, psoriasis).
\end{abstract}

Results: A prior malignancy was reported in 122 out of 5,120 patients. Fifty-eight of these patients had received antiTNFa agents, 9 anakinra, and 55 conventional DMARDs at study entry. In 14 patients (ever exposed to anti-TNFa: eight, to anakinra: one) 15 recurrent cancers were observed. The average time period since the onset of the first malignancy was nine years. Crude recurrence rates per 1,000 patient-years (pyrs) were 45.5 for patients exposed to anti-TNFa agents, 32.3 for anakinra patients and 31.4 for patients exposed to DMARDs only (Incidence rate ratio anti-TNFa vs. DMARD $=1.4, P=0.6$.). In patients without prior cancer, 74 patients (70\% female, mean age: 61.3 ) developed a first malignancy during the observation. This corresponds to an incidence rate (IR) of 6.0/1,000 pyrs. Forty-four of these patients were ever exposed to anti-TNFa treatment ( $I R=5.1 / 1,000$ pyrs). In a nested case-control study comparing cancer patients to cancer-free controls, 44 of the cancer patients and 44 of the cancer-free controls were ever exposed to anti-TNFa agents $(P=1.0)$.

Conclusions: No significant differences in the overall incidence of malignancies in patients exposed or unexposed to anti-TNFa or anakinra treatment were found. The same applied to the risk of recurrent malignancies. However, in particular this last finding needs further validation in larger data sets.

\section{Introduction}

Patients with rheumatoid arthritis (RA) and other chronic inflammatory diseases are often subject to prolonged treatment with immunosuppressive drugs which modify the immunologic pathways involved in the pathogenesis of RA.

\footnotetext{
* Correspondence: Strangfeld@drfz.de

1 German Rheumatism Research Centre Berlin, a Leibniz institute, Charitéplatz 1, 10117 Berlin, Germany
}

Tumor necrosis factor alpha $(\mathrm{TNF} \alpha)$ is among the cytokines that play a major role in the inflammatory process of rheumatic diseases. Its inhibition leads to substantial improvement in clinical signs and symptoms in a majority of patients. To date three different agents are available as monoclonal antibodies or receptor fusion antagonists of $\mathrm{TNF} \alpha$. The finding that TNF $\alpha$ is able to induce tumor cell apoptosis led it to be named TNF before its role in the 
inflammatory process was revealed [1]. TNF $\alpha$ or rather its nuclear factor-kappa B pathway acts as an early tumor suppressor [2]. This property led to concerns about a possibly increased risk of malignancies when drugs blocking TNF $\alpha$ will be used for long-term treatment.

These concerns were supported by two meta-analyses of randomized controlled trial data. In their first aggregate data meta-analysis of nine randomized controlled trials (RCTs) of anti-TNF $\alpha$ antibody therapies (infliximab and adalimumab) versus placebo in patients with rheumatoid arthritis, Bongartz et al. [3] found a significantly increased risk for malignancies in anti-TNF $\alpha$ versus placebo treated patients with a pooled odds ratio of 3.3 (95\% CI: 1.2 to 9.1$)$. In their second meta-analysis Bongartz et al. [4] found a higher malignancy risk also in patients treated with etanercept as compared to the control group, although the relative risk estimate did not achieve statistical significance (Hazard ratio (HR) of 1.84 [95\% CI: 0.79 to 4.28$]$ ]).

Considering the strict criteria for the inclusion of patients and the thorough monitoring process preceding controlled trials there might be an even higher risk when unselected RA patients are treated with anti-TNF $\alpha$ agents in daily rheumatologic care. Therefore, real-world data from studies systematically observing patients treated with these agents for long periods are of high importance.

Patients with prior malignancy are usually excluded from participation in RCTs and most clinical recommendations do not encourage treating these patients with anti-TNF $\alpha$. However, this treatment might be the best therapeutic option for their inflammatory disease. Information regarding the safety of biologic agents prescribed to patients with prior malignancies is available only from two abstracts from the British Society of Rheumatology Biologics Register (BSRBR) $[5,6]$, one of them indicating a possibly increased recurrence risk for melanoma [6].

According to the national recommendations of the German Society of Rheumatology biologic agents should be prescribed after failure of at least six months of treatment with two conventional DMARDs (including methotrexate (MTX)) alone or in combination [7].

The German biologics register RABBIT is an ongoing, nationwide prospective cohort study started in 2001 with the approval of the first biologic agents in Germany. It was established with the aim to assess the long-term safety of biologic agents including TNF $\alpha$ blockers. Time points of follow-up and assessments are identical for patients treated with biologic agents and for those under therapy with conventional DMARDs.

We used the data from RABBIT to investigate the frequency of developing a first malignancy in patients treated with anti-TNF $\alpha$ agents compared to those treated with conventional DMARDs and to study the risk of patients with a history of malignancy receiving anti-TNF $\alpha$ therapy.

\section{Materials and methods Patients}

Patients aged 18 to 75 years meeting the American College of Rheumatology (ACR) criteria for RA are eligible to be enrolled in RABBIT at the start of treatment with a biologic agent or a conventional DMARD after failure of at least one other DMARD. Prior to enrollment all patients gave their informed consent. Patients enrolled between 01 May 2001 and 31 December 2006 (end of recruitment to this cohort) were included in the following analyses provided at least one follow-up visit and the baseline status regarding comorbid conditions were available. Patients were followed up independent of any change in their treatment regimes. Information about patients who missed two or more consecutive follow-up visits was obtained by contacting the treating physicians, and if necessary the patients themselves, their relatives or the local health authorities to determine the patient's vital status. The reasons for dropout and the causes of death were ascertained. Details of inclusion criteria for RABBIT were previously reported $[8,9]$. The ethics committee of the Charité University School of Medicine, Berlin, approved the study protocol.

\section{Assessments}

At baseline and at predefined time points of follow-up $(3,6$, $12,18,24,30,36,48,60$ months) rheumatologists assessed the clinical status including the components of the disease activity score based on 28 joint counts (DAS28) and reported treatment details and serious and non-serious adverse events according to the International Conference on Harmonization E2A guidelines [10]. All adverse events were coded using the Medical Dictionary for Regulatory Affairs (MedDRA) [11] by one of the authors (AS). Reported malignancies were considered as events of interest, and an additional query asking for diagnostic and treatment details and cancer history was sent to the reporting rheumatologist. Only in five cases we did not receive any further information. In $50 \%$ of the cases hospital discharge letters with the exact histopathologic results were sent to us.

At study entry rheumatologists reported co-morbidities for every patient on a list of 23 diseases which include among others: prior malignancy or lymphoma, chronic obstructive pulmonary disease (COPD), other chronic lung disease, chronic renal disease, chronic gastrointestinal disease, chronic liver disease, psoriasis, and chronic viral disease. Patients assessed their pain, general health, disability and socioeconomic status. The Hannover Functional Status Questionnaire (Funktionsfragebogen Hannover, FFbH) was used to assess disability. Scores are expressed as percentage of full function (range 0 to 100) and can be transformed into Health Assessment Questionnaire (HAQ) values [12]. Smoking habits were not assessed at baseline but only after $24,48,60$ months. Since this resulted in a high percentage of missing smoking information we did not include smok- 
ing in the multivariate analyses. Nevertheless, in the nested case control study we were able to include smoking by using the missing information as one matching criterion.

\section{Statistical analysis}

Prior malignancies and tumor recurrence. All patients meeting the study inclusion criteria were stratified by their prior malignancy status. For all patients prior malignancies were reported by the rheumatologist at study entry. Patients with or without prior malignancy were compared with respect to patient characteristics and treatment. In patients with a recurrent malignancy during the observation in RABBIT we analysed whether treatment was associated with recurrence. We defined recurrency as development of any cancer after a history of a prior malignancy, irrespective of the type of the recurrent tumor.

\section{Tumor incidence}

We analysed the tumor incidence during the observation period in all patients without prior malignancy. We included all types of cancer except for basal cell carcinomas. One M. Bowen was reported and included. There was no report of other carcinomas in situ. The observed number of incident cancers was compared with the expected number calculated from population data [13]. Cox regression was used to analyse the effects of treatment and to adjust for demographic and clinical data. Only exposure times after enrollment in the RABBIT register were taken into account. Patients were considered to be exposed to anti-TNF $\alpha$ treatment for the time period from the start of anti-TNF $\alpha$ treatment to the end of follow-up (ever exposed-approach). The same definition was used for anakinra exposure. Because of the applied ever exposed-approach patients could have been exposed to both, anti-TNF $\alpha$ agents and anakinra. Patients (or follow-up time of patients) not (yet) exposed to anti-TNF $\alpha$ or anakinra were considered as exposed to DMARDs only.

The following baseline characteristics were included in the risk assessment: age, gender, disease duration, rheumatoid factor, functional capacity (measured by the $\mathrm{FFbH}$ ), selected previous treatment exposures (cyclosporine or azathioprine) [14], and co-morbid conditions.

Since nearly all $(98.3 \%)$ of our patients were ever exposed to methotrexate and only a small minority $(0.6 \%)$ to cyclosphosphamide we were not able to investigate a specific cancer risk associated with these agents. A preliminary analysis blinded for treatment assignment revealed associations between the frequency of cancer and COPD, chronic gastrointestinal diseases and chronic renal diseases. Other co-morbidities, such as chronic lung diseases in general, are known to be associated with increased cancer risk. Therefore, the following comorbid conditions were included in the Cox regression analysis: COPD, other chronic lung disease, chronic renal disease, chronic gastrointestinal disease, chronic liver disease, and psoriasis. Furthermore, we investigated the impact of exposure to anti-
TNF $\alpha$ agents as well as the impact of long-term high disease activity (measured by time-averaged DAS28 scores) on the risk of cancer. For this analysis, the mean of all DAS28 scores measured more than six months before an event were included as time-dependent co-variables into the Cox regression analysis. Disease activity during the six months prior to a malignancy diagnosis was not considered since it may have been influenced by the carcinogenesis. For malignancies that developed within the first six months of observation, the DAS2 8 measured at study entry was used. On average $7 \%$ of the DAS28 values at follow-up were missing. To minimize possible bias missing values were imputed before the time-averaged scores were calculated. The expectation-maximisation (EM) algorithm most appropriate for approximately normally distributed variables such as the DAS28 was applied for estimation and imputation [15]. Calculations were performed using the SAS procedures MI and PHREG. A test based on the analysis of Schoenfeld residuals of Cox regression was used to investigate the invariance of the HR over time [16].

The control for confounding factors by Cox regression analysis may be insufficient since smoking could not be included and two possible risk factors found in our preliminary analysis (see above) were observed in less than $5 \%$ of the patients. Our statistical analysis plan therefore stipulated to perform a nested case control study as our main analysis of the risk of incident cancer. For each case with an incident cancer, a cancer-free control patient was selected who was compatible with the following matching criteria: gender, smoking status, and six co-morbid conditions (same as those used in the Cox regression). Cases with valid data of smoking status were matched to controls with the same smoking status and patients with missing information regarding smoking status were matched to controls who also had no smoking status data. After matching for eight categorical variables, a control patient was selected who fitted best to the case concerning age, follow-up time and DAS28 at baseline. Standardized Mahalanobis metric was used for measuring similarity. The availability of 4,923 possible controls permitted use of this detailed matching algorithm. Mc Nemar test was used to compare the numbers of patients exposed to biologics (anti-TNF $\alpha$ agents or anakinra) between patients and matched controls. For further comparisons within the nested case control study, paired ttest and Wilcoxon test were applied as appropriate. Chisquare test, t-test and Mann-Whitney test were used for statistical comparisons of patient's characteristics at baseline. $P$-values $<0.05$ were considered statistically significant.

\section{Results}

Patient characteristics and treatment status at study entry

Between 01 May 2001 and 31 December 2006, 5,279 patients were enrolled in RABBIT. One hundred fifty-nine patients were excluded from this analysis because of miss- 
ing follow-up information or missing co-morbid condition status (Figure 1). Their baseline characteristics (age, DAS28, function, co-morbidity status) were not statistically different from the remaining 5,120 patients. Those were stratified according to their prior malignancy status, and both groups were analysed separately. A total of 124 prior malignancies were found in 122 patients: 6 lymphomas (DMARDs: 2, anti-TNF $\alpha$ : 4), and 118 solid tumors (DMARDs: 54, anakinra: 9, anti-TNFa: 55)]. Patients with prior malignancies were significantly older $(\mathrm{P}<0.001)$, had a lower functional capacity (56\% of full function vs. $60 \%$ of full function) and a higher frequency of chronic gastrointestinal disease than patients without prior malignancy (Table 1). Within both strata, we found that patients receiving biologics had significantly more active disease, and were more limited in activities of daily living $(\mathrm{FFbH})$. As reported previously, there were no significant differences in the clinical characteristics of patients receiving etanercept, adalimumab, or infliximab [17], whereas anakinra patients had more treatment failures with DMARDs and a lower functional capacity $(\mathrm{FFbH})$ than anti-TNF $\alpha$ patients. Because of the differing modes of action and the differences in the clinical characteristics, separate results are provided in the following analyses for patients receiving anti-TNF $\alpha$ agents and patients receiving anakinra.

Patients with a prior malignancy were insignificantly less frequently treated with anti-TNF $\alpha$ agents or anakinra at inclusion than patients without prior malignancy (Figure 1, Table 1). The adjusted OR to receive biologics (adjusted for age, sex, disability, disease activity) for patients with prior malignancies compared to those without was $0.7(95 \% \mathrm{CI}$ : 0.5 to 1.1). Detailed information including the exact type of malignancy was reported in 54 of the 124 prior malignancies. We found some differences regarding the spectrum of those malignancies in anti-TNF $\alpha$ vs. DMARD treated patients: At study entry all nine cases with prior prostatic

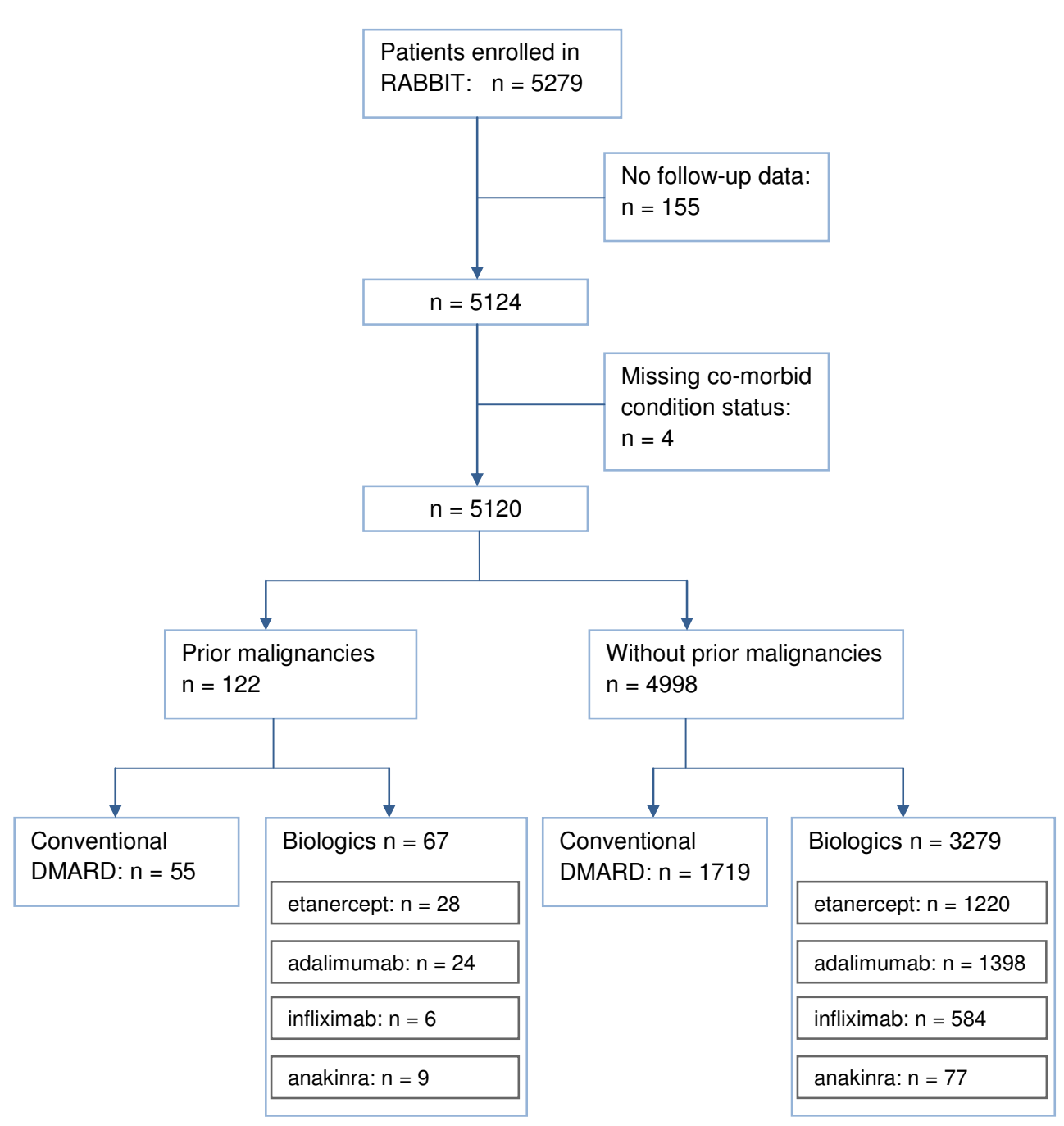

Figure 1 Flow chart of patients included in the analysis. 


\begin{tabular}{|c|c|c|c|c|c|c|c|c|c|}
\hline & \multicolumn{3}{|c|}{ Patients with prior malignancy } & \multicolumn{5}{|c|}{ Patients without prior malignancy } & \multirow[b]{2}{*}{ P\#\# } \\
\hline & Biologic & Control & Total & $\mathbf{P} \#$ & Biologic & Control & Total & $\mathbf{P} \#$ & \\
\hline $\mathbf{n}$ & 67 & 55 & 122 & & 3279 & 1719 & 4998 & & \\
\hline Female $\mathbf{n}(\%)$ & $45(67.2)$ & $41(74.5)$ & $86(70.5)$ & 0.43 & $2564(78.2)$ & $1353(78.7)$ & $3917(78.4)$ & 0.671 & 0.047 \\
\hline Age (mean, SD) & $64.0(9.0)$ & $63.2(7.7)$ & $63.7(8.4)$ & 0.62 & $53.6(12.3)$ & $55.9(11.5)$ & $54.4(12.1)$ & $<0.0001$ & $<0.001$ \\
\hline $\begin{array}{l}\text { Disease duration } \\
\text { (yrs), median (IQR) }\end{array}$ & $10(6,16.5)$ & $7(3,13)$ & $9(4,16)$ & 0.02 & $9(5,17)$ & $6(2.5,12)$ & $8(4,15)$ & $<0.0001$ & 0.286 \\
\hline $\begin{array}{l}\text { Time from prior } \\
\text { cancer to study } \\
\text { entry (yrs), median } \\
\text { (IQR) }\end{array}$ & $5(2,9)$ & $5(3,11)$ & $5(2,10)$ & 0.77 & & & & & \\
\hline $\begin{array}{l}\text { Follow-up time } \\
\text { (yrs), median (IQR) }\end{array}$ & $2.1(1.4,3.0)$ & $2.5(1.0,4.0)$ & $2.1(1.1,3.1)$ & 0.43 & $2.4(1.4,3.1)$ & $2.5(1.3,3.3)$ & $2.4(1.3,3.1)$ & 0.081 & 0.611 \\
\hline $\begin{array}{l}\text { Rheumatoid factor } \\
\text { positive } \mathrm{n}(\%)\end{array}$ & $53(79.1)$ & $46(83.6)$ & $99(81.1)$ & 0.64 & $2629(80.2)$ & $1225(71.3)$ & $3854(77.1)$ & $<0.0001$ & 0.327 \\
\hline DAS28 (mean, SD) & $5.7(1.3)$ & $5.4(1.1)$ & $5.6(1.2)$ & 0.04 & $5.8(1.3)$ & $5.0(1.3)$ & $5.5(1.3)$ & $<0.0001$ & 0.282 \\
\hline $\begin{array}{l}\text { ESR }(\mathrm{mm} / \mathrm{h}) \text {, median } \\
\text { (IQR) }\end{array}$ & $38(18,51)$ & $26(15,42)$ & $32(17,50)$ & 0.12 & $30(16,48)$ & $22(12,38)$ & $27(14,44)$ & $<0.0001$ & 0.080 \\
\hline $\begin{array}{l}\text { CRP (mg/L), median } \\
\text { (IQR) }\end{array}$ & $25(10,46)$ & $15(8,30)$ & $19(9,43)$ & 0.07 & $17(8,38)$ & $12(5,27)$ & $15(7,34)$ & $<0.0001$ & 0.146 \\
\hline FFbH (mean, SD) & $52.1(21.3)$ & $59.9(23.5)$ & $55.7(22.5)$ & 0.02 & $57.0(23.0)$ & $66.8(21.4)$ & $60.4(22.9)$ & $<0.0001$ & 0.025 \\
\hline Smoking ever n (\%) & $23(57.5)$ & $15(55.6)$ & $38(56.7)$ & 1.00 & $878(46.9)$ & $473(46.4)$ & $1351(46.7)$ & 0.328 & 0.13 \\
\hline $\begin{array}{l}\text { No. of previous } \\
\text { DMARDs (mean, SD) }\end{array}$ & $3.7(1.5)$ & $1.9(1.0)$ & $2.9(1.6)$ & $<0.001$ & $3.6(1.4)$ & $1.9(1.1)$ & $2.9(1.5)$ & $<0.0001$ & 0.656 \\
\hline COPD n (\%) & $3(4.4)$ & $6(10.9)$ & $9(7.3)$ & 0.30 & $163(5)$ & $81(4.7)$ & $244(4.9)$ & 0.685 & 0.205 \\
\hline $\begin{array}{l}\text { Chronic renal } \\
\text { disease n (\%) }\end{array}$ & $4(5.9)$ & $1(1.8)$ & $5(4.1)$ & 0.38 & $134(4.1)$ & $29(1.7)$ & $163(3.3)$ & $<0.0001$ & 0.603 \\
\hline $\begin{array}{l}\text { Chronic lung } \\
\text { disease } \mathrm{n}(\%)\end{array}$ & $5(7.4)$ & $1(1.8)$ & $6(4.9)$ & 0.22 & $93(2.8)$ & $29(1.7)$ & $122(2.4)$ & 0.012 & 0.129 \\
\hline $\begin{array}{l}\text { Chronic } \\
\text { gastrointest. } \\
\text { disease } \mathrm{n}(\%)\end{array}$ & $12(17.6)$ & $5(9.1)$ & $17(13.9)$ & 0.2 & $281(8.6)$ & $138(8.0)$ & $419(8.4)$ & 0.510 & 0.047 \\
\hline
\end{tabular}


cancer were treated with biologics (seven with anti-TNF $\alpha$ and two with anakinra) whereas three patients with prior bladder cancer were found in the DMARD treated group and one patient was treated with anakinra. Patients with prior breast cancer were less frequently treated with biologics $(n=11)$ than with DMARDs $(n=14)$ at inclusion. The time between onset of the prior malignancy and study entry did not differ between the treatment groups. The median time was five years (IQR: 2 to 9) for patients receiving biologics (anti-TNF $\alpha$ : four years ( 2 to 10 ); anakinra: six years (5 to 9)) and five years (3 to 11) for patients receiving conventional DMARDs $(P=0.77)$. In $28(45.9 \%)$ of the patients treated with biologics (27 with anti-TNF $\alpha$ and 1 with anakinra) and in $22(40.7 \%)$ patients in the DMARD group the time since the last tumor diagnosis was less than five years when treatment with the respective agent started.

\section{Recurrence of a prior malignancy}

During follow-up 15 recurrent cancers were observed in 14 patients including 14 recurrences of the same type and site as the prior tumor and one metastasis of unknown origin (Table 2). Nine recurrences were seen in eight patients under treatment with anti-TNF $\alpha$ agents, one in an anakinra patient and five in patients exposed to DMARDs only. The corresponding crude incidence rates were 45.5 (95\% CI: 20.8 to 86.3 )/1,000 patient years (pyrs) for patients receiving anti-TNF $\alpha$ agents, 32.3 (95\%CI: 0.8 to 179.7$) / 1,000$ pyrs for patients treated with anakinra and $31.4(95 \% \mathrm{CI}$ : 10.2 to 73.4 ) $/ 1,000$ pyrs for DMARD treated patients (incidence rate ratio anti-TNF $\alpha$ agents vs. DMARDs: 1.4 (95\% CI: 0.5 to 5.5) $P=0.63$ ).

The mean time span between the prior tumor and the diagnosis of the new tumor was 9.5 (SD: 7.8), 9.1, and 9.2 (8.8.) years for patients exposed to anti-TNF $\alpha$ agents, anakinra, or conventional DMARDs, respectively. Three patients developed a recurrent cancer less than five years after the previous cancer (two in the anti-TNF $\alpha$ treated group, one in the DMARD group).

Four of the five patients who were treated with conventional DMARDs only and experienced a recurrence of their prior malignancy died (signet-ring-cell carcinoma, metastasis of unknown origin, breast cancer, lung cancer). One out of the eight patients under treatment with anti-TNF $\alpha$ died (breast cancer), and the one patient under treatment with anakinra (lung cancer) died. All other patients with recurrences were still alive at the time of the analysis.

\section{Incidence of tumors in patients without a prior malignancy Comparison of the tumor incidence with the general population}

Seventy-four patients among the 4,998 patients who did not have a prior malignancy developed an incident tumor. This is an overall incidence rate of 6.0 per 1,000 pyrs [ $95 \%$ CI: 4.7 to 7.6$]$. The figures were 5.1 per 1,000 pyrs $(95 \%$ CI:
3.7 to 6.9) for patients exposed to anti-TNF $\alpha, 7.2$ per 1,000 pyrs (95\% CI: 2.4 to 16.9 ) for patients exposed to anakinra and 8.4 per 1,000 pyrs ( $95 \%$ CI: 5.7 to 12.0 ) for patients exposed to conventional DMARDs. For some of the cancer sites the observed incidence rates in both groups were lower than the age and sex adjusted rates as expected from the general population (for example, breast, male and female reproductive organs and colon cancer) [13] (Figure 2). Higher rates were observed for non-Hodgkin's lymphoma in patients exposed to biologics and for pancreatic cancer in the group not exposed to biologics. None of the site specific differences were statistically significant when the $P$-values were adjusted for repeated significance testing. Taking into account all malignancies, the number of observed cancers in patients exposed to anti-TNF $\alpha$ agents was non-significantly lower than the expected number from the general population (standardized incidence rate ratio: $0.75,95 \% \mathrm{CI}$ : 0.54 to 1.01). No difference was found for patients not exposed to biologics.

\section{Comparison of patients with and without incident tumors in} patients with no prior cancer

Overall, patients who developed malignancies during the study period had more co-morbidities than those who did not $($ mean $=2.5(\mathrm{SD}=2.1)$ vs. $1.7(1.9))$. Higher rates were observed for COPD (11/74 (14.9\%) vs. 223/4924 (4.5\%), $P$ $<0.0001)$, chronic gastrointestinal diseases ((13/74 (17.6\%) vs. $406 / 4924(8.2 \%), P=0.008)$, and chronic renal diseases (4/74 (5.4\%) vs. $159 / 4924$ (3.2\%), $P=0.22)$. Furthermore, site specific associations were observed for gastric/colorectal cancer in 2/419 patients with a chronic gastrointestinal disease vs. $3 / 4579$ in the remaining patients $(P=0.06)$, and for bladder cancer/renal cancer in $1 / 163$ patients with chronic renal diseases vs. $3 / 4835$ in the remaining patients $(P=0.12)$.

Crude cancer incidence rates were therefore higher in patients with specific comorbid conditions but also in those with a highly active disease (Table 3 ).

The univariate analysis showed that patients with a very active disease (DAS28 $>5.1$, mean: 5.93) during follow-up had a two times higher cancer risk than those with low disease activity (DAS28 <3.2, mean: 2.75) (Table 4).

In the multivariate analysis the development of an incident tumor was strongly associated with age $(\mathrm{HR}=1.71$; 95\% CI: 1.3 to 2.2 per 10 years increase in age, $P<0.0001$ ) and COPD (HR $=2.63 ; 95 \% \mathrm{CI}: 1.4$ to $5.0, P=0.004)$ (Table 4). A higher cancer risk was also observed for patients with chronic gastrointestinal diseases whereas no significant associations were found for other co-morbid conditions (other chronic lung diseases, psoriasis, chronic liver disease) or for gender (HR (males vs. females) $=1.46$; 95\% CI: 0.9 to $2.4, P=0.14$ ). Likewise, associations for patients ever exposed to cyclosporine $(\mathrm{n}=582, P=0.24)$ or azathioprine $(\mathrm{n}=599, P=0.32)$ were not statistically significant. 
In patients exposed to anti-TNF $\alpha$ agents we observed a non-significantly decreased risk for developing a malignancy compared to patients treated with conventional DMARDs (adjusted HR $=0.70$; $95 \%$ CI: 0.44 to $1.12, P=$ $0.13)$.

\section{Time dependency of the hazard risk in patients without prior cancer}

The mean time until the onset of the malignancy was 25.0 (16.8) months for patients exposed to anti-TNF $\alpha$ agents, 14.8 (9.1) for anakinra and 17.4 (15.7) months for patients not exposed to biologics. Ten of the 44 malignancies of anti-TNF $\alpha$-exposed patients developed in the first year compared to 15 of 30 malignancies in non-exposed patients. This corresponds to adjusted hazard ratios of 0.4 for the first and 1.0 for the second to fourth year. We analysed this possible time trend in the hazard ratio by means of an analysis of standardized Schoenfeld residuals of the Cox regression. The trend was, however, not statistically significant $(P=0.13)$.

\section{Nested case-control study}

The main analysis to assess the risk of developing an incident tumor under treatment with anti-TNF $\alpha$ agents was conducted as a nested case control study. Each case with an incident malignancy was matched to one control patient without malignancy (see Methods). Due to the high number of possible matching partners, matching was successful for all parameters involved. Cases with incident malignancy had lower baseline functional capacity than those without cancer (Table 5). There was no significant difference concerning treatment exposure: Forty-four (59.5\%) of the cases and $45(60.8 \%)$ of the controls had ever been exposed to biologics. The numbers of cases ever exposed to etanercept, adalimumab, infliximab, or anakinra $(\mathrm{n}=22 ; \mathrm{n}=20 ; \mathrm{n}=$ $16 ; n=5$, respectively) did not differ significantly from the numbers of controls ever exposed to these therapies ( $\mathrm{n}=27$; $\mathrm{n}=24 ; \mathrm{n}=10 ; \mathrm{n}=5$, respectively). A separate analysis of malignancies observed in the first year (anti-TNF $\alpha$ exposed $10 / 25$ cases vs. 11/25 controls) and in the second to fourth year (anti-TNF $\alpha$ exposed: $34 / 49$ cases vs. $33 / 49$ controls) did not show any significant difference between the groups or a significant time trend.

An insignificantly higher rate of exposure to anti-TNFa agents was found in patients who developed non-Hodgkin's lymphoma.

\section{Discussion}

First, in patients with prior malignancy we did not find a significant increase in the risk of recurrent tumors under treatment with anti-TNF $\alpha$ agents compared to conventional DMARDs, even though there was a higher recurrence rate under anti-TNF $\alpha$ treatment $(\mathrm{IRR}=1.4, P=0.6)$.

Table 2: Recurrence of prior malignancy by type and treatment

Ever exposed to

\begin{tabular}{|c|c|c|c|c|}
\hline & Total & Anti-TNFa & Anakinra & $\begin{array}{l}\text { Conventional } \\
\text { DMARD only }\end{array}$ \\
\hline $\begin{array}{l}\mathrm{N} \text { with prior } \\
\text { malignancy }\end{array}$ & 122 & 72 & 11 & 43 \\
\hline $\begin{array}{l}\text { Patient-years of } \\
\text { follow-up }\end{array}$ & 379 & 198 & 31 & 159 \\
\hline $\begin{array}{l}\text { Recurrent } \\
\text { malignancies }\end{array}$ & 15 & $9(5 \mathrm{f}, 4 \mathrm{~m})$ & $1(\mathrm{~m})$ & $5(4 \mathrm{f}, 1 \mathrm{~m})$ \\
\hline Breast cancer & 5 & $4(f)$ & - & $1(\mathrm{f})$ \\
\hline Lung cancer & 3 & $1(\mathrm{~m})$ & $1(\mathrm{~m})$ & $1(\mathrm{f})$ \\
\hline Bladder cancer & 2 & $1(\mathrm{~m})^{\#}$ & - & 1 (f) \\
\hline Liposarcoma & 1 & $1(\mathrm{~m})$ & - & - \\
\hline Melanoma & 1 & $1(\mathrm{f})$ & & \\
\hline $\begin{array}{l}\text { Signet-ring cell } \\
\text { carcinoma }\end{array}$ & 1 & - & - & 1 (f) \\
\hline Testicular cancer & 1 & $1(\mathrm{~m})^{\#}$ & - & - \\
\hline $\begin{array}{l}\text { Metastasis } \\
\text { of unknown } \\
\text { origin }\end{array}$ & 1 & & & $1(\mathrm{~m})$ \\
\hline
\end{tabular}

$M=$ male, $f=$ female, "testicular cancer and bladder cancer in one patient 


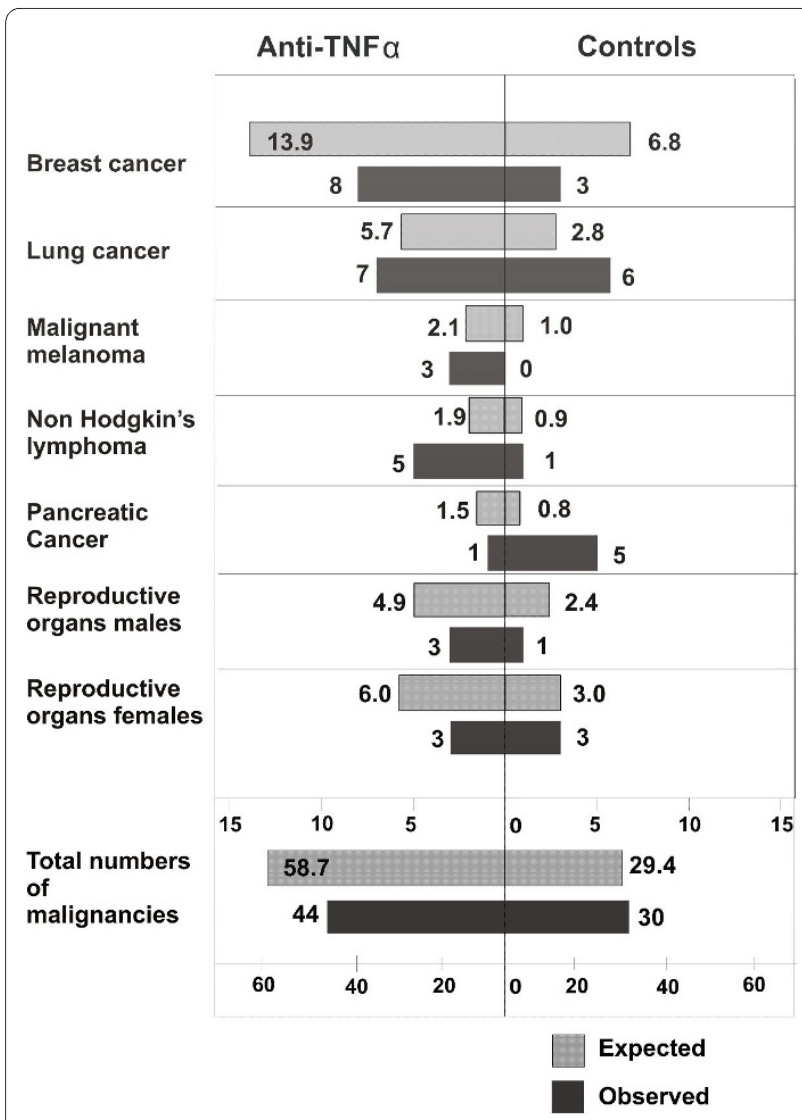

Figure 2 Observed numbers of cancers and expected numbers from the general population, standardized by age and sex.

Second, patients without prior malignancy did not have higher rates of incident tumors when they were exposed to biologics compared to unexposed patients.

The strength of our study is that all data on incident and recurrent tumours originate from a prospective, closely monitored observational cohort study established for the purpose of pharmacovigilance. Data were collected in an identical manner and by the same physicians for patients treated with biologic agents or with conventional DMARDs. Due to stringent and close monitoring, drop-out rates were less than $5 \%$ per year. Additionally, for all patients lost to follow-up the vital status was ascertained or, if appropriate, the cause of death.

To investigate the occurrence of incident malignancies, we followed three different methodological approaches: a nested case-control study, a multivariate Cox regression and a comparison with population data.

Of note, we excluded basal cell carcinoma from all types of our analysis since no age and sex specific population rates were available.

The design of the nested case control study allowed us to adjust for differences in clinical and demographic parameters (for example, selected co-morbidities, smoking status) which are related to treatment assignment but which are also associated with the risk of cancer. We therefore consider the nested-case control analysis our central assessment of the risk of incident malignancies under treatment with anti-TNF $\alpha$ agents. However, since only a very small proportion of the patients were included in the nested case control analysis and therefore information of a large number of patients was not used, we decided to apply a multivariate Cox regression analysis in addition.

A potential weakness of this study is that we only investigated the overall cancer risk. The risk for site-specific cancers has not been analyzed due to the limited numbers of events. In addition, due to the relatively short time of observation no conclusions can be drawn beyond the scope of four years of exposure.

Limitations of the analysis of tumor recurrence include the relatively small sample size and the fact that physicians were less likely to prescribe cytokine inhibitors for patients with prior malignancy than for those without such a history. Furthermore, our data indicate that physicians might have made different treatment decisions for patients with different prior tumors. We therefore must exhibit caution in drawing firm conclusions.

The same applies for the interpretation of the data for anakinra treated patients: only a few patients in the cohort were ever treated with anakinra, most of them were also exposed to anti-TNF $\alpha$ agents. Therefore, malignancies occurring in this group must be interpreted carefully, taking patient selection (also seen in differing baseline characteristics) into account.

Our results differ from those reported by the British Society for Rheumatology Biologics Registry (BSRBR) [6]. Dixon and co-workers analyzed 177 patients with prior malignancies treated with anti-TNF $\alpha$ agents with a median follow-up of three years and found no increased risk for recurrent malignant diseases compared to 118 patients with prior malignancies treated with conventional DMARDs and followed-up for 1.9 years. Their crude incidence rates were 25.3 and 41.9 per 1,000 patient-years for patients treated with anti-TNF $\alpha$ agents and conventional DMARDs, respectively, compared to 45.5 and 31.4 per 1,000 patients-years in our study. In an earlier analysis of the BSRBR [5] a total of 154 patients in the anti-TNF $\alpha$ cohort had a previous malignancy and six (4\%) developed a new malignancy. However, of these malignancies only one was a local recurrence which is in contrast to our findings. In our study, in 14 out of the 15 recurrences the observed malignancies were true recurrences of the prior tumor with the same type and site. Only in one of our patients with pulmonary and bone metastases the origin of the malignancy remained unknown. This patient had a history of testicular cancer 20 years before.

Our investigations regarding the risk of developing an incident malignancy were motivated by two meta-analyses of randomized controlled trials which suggested an 


\begin{tabular}{|c|c|c|c|c|}
\hline & $n$ of $C A$ & $\mathbf{n}$ & pyrs & IR \\
\hline \multicolumn{5}{|l|}{$\begin{array}{l}\text { Characteristics at } \\
\text { baseline }\end{array}$} \\
\hline \multicolumn{5}{|l|}{$\begin{array}{l}\text { Age (per } 10 \text { yrs } \\
\text { increase) }\end{array}$} \\
\hline Female & 52 & 3,917 & 9,687 & 5.4 \\
\hline Male & 22 & 1,081 & 2,554 & 8.6 \\
\hline \multicolumn{5}{|l|}{ Co-morbid conditions: } \\
\hline \multicolumn{5}{|l|}{ COPD } \\
\hline No & 63 & 4,754 & 11,677 & 5.4 \\
\hline Yes & 11 & 244 & 564 & 19.5 \\
\hline \multicolumn{5}{|l|}{$\begin{array}{l}\text { Gastrointestinal } \\
\text { disease }\end{array}$} \\
\hline No & 61 & 4,579 & 11,153 & 5.5 \\
\hline Yes & 13 & 419 & 1,088 & 11.9 \\
\hline \multicolumn{5}{|l|}{ Renal disease } \\
\hline No & 70 & 4,835 & 11,884 & 5.9 \\
\hline Yes & 4 & 163 & 357 & 11.2 \\
\hline \multicolumn{5}{|l|}{$\begin{array}{l}\text { Characteristics at } \\
\text { follow-up }\end{array}$} \\
\hline \multicolumn{5}{|l|}{ DAS28 } \\
\hline$<3.2$ & 6 & 787 & 2,165 & 2.8 \\
\hline 3.2 to 5.1 & 34 & 2,823 & 7,341 & 4.6 \\
\hline$>5.1$ & 34 & 1,388 & 2,735 & 12.4 \\
\hline \multicolumn{5}{|l|}{ Ever exposed to } \\
\hline $\begin{array}{l}\text { Conventional DMARDs } \\
\text { only }\end{array}$ & 30 & 1,684 \# & 3,561 & 8.4 \\
\hline Anti-TNF agents & 44 & 3,651 * & 8,558 & 5.1 \\
\hline Anakinra & 5 & $247 \$$ & 690 & 7.2 \\
\hline
\end{tabular}

CA: malignancies, $n=$ number of cases, pyrs = follow-up time in patient years, IR = crude incidence rate per 1,000 pyrs.

\#35 of the patients in the DMARD cohort were exposed to anti-TNF agents before inclusion in the study. According to the ever exposed approach their follow-up time was assigned to the anti-TNF treated group.

* Patients included in this group are patients who were included in the study with the start of an anti-TNF agent $(n=3,201)$ and patients who changed during follow-up from DMARD or anakinra treatment to anti-TNF treatment

$\$ 223$ of the 247 pts were exposed to anakinra and anti-TNF agents, they experienced five malignancies.

increased risk of malignancies associated with the treatment with one of the TNF $\alpha$ blocking agents: adalimumab, infliximab, or etanercept $[3,4]$. The results of these meta-analyses are in contrast with those from observational cohort studies or national cancer registries, in which such an increased risk was not observed $[18,19]$. The methodological weaknesses of the first meta-analysis investigating the risk for treatment with adalimumab or infliximab have already been discussed elsewhere [20]. However, the repeated finding of an increased cancer risk also in patients treated with etanercept $[3,4]$ requires further research, even if it did not achieve statistical significance. These metaanalyses support the early mobilization hypothesis implying a high risk within the first months of treatment with antiTNF $\alpha$ agents.

However, our results for the first year are in contrast to the meta-analyses reported by Bongartz et al. [3,4]. In the first year of treatment patients receiving biologics had a lower risk for developing an incident malignancy than those 
Table 4: Hazard ratios of developing a malignancy

\begin{tabular}{|c|c|c|c|c|c|c|}
\hline & \multicolumn{3}{|c|}{ Univariate Cox regression } & \multicolumn{3}{|c|}{ Multivariate analysis } \\
\hline & HR & $95 \% \mathrm{Cl}$ & $\mathbf{P}$ & adjusted HR & $95 \% \mathrm{Cl}$ & $\mathbf{P}$ \\
\hline \multicolumn{7}{|l|}{$\begin{array}{l}\text { Characteristics at } \\
\text { baseline }\end{array}$} \\
\hline $\begin{array}{l}\text { Age (per } 10 \text { yrs } \\
\text { increase) }\end{array}$ & 1.82 & 1.44 to 2.31 & $<0.0001$ & 1.71 & 1.35 to 2.17 & $<0.0001$ \\
\hline Male vs. female & 1.61 & 0.98 to 2.65 & 0.062 & 1.47 & 0.89 to 2.43 & 0.13 \\
\hline \multicolumn{7}{|l|}{$\begin{array}{l}\text { Co-morbid } \\
\text { conditions: }\end{array}$} \\
\hline COPD & 3.64 & 1.92 to 6.91 & $<0.0001$ & 2.63 & 1.37 to 5.04 & 0.004 \\
\hline $\begin{array}{l}\text { Gastrointestinal } \\
\text { disease }\end{array}$ & 2.19 & 1.20 to 3.98 & 0.010 & 1.81 & 0.99 to 3.30 & 0.0534 \\
\hline Renal disease & 1.93 & 0.70 to 5.28 & 0.20 & & & \\
\hline \multicolumn{7}{|l|}{$\begin{array}{l}\text { Characteristics at } \\
\text { follow-up }\end{array}$} \\
\hline $\begin{array}{l}\text { DAS28 (per unit } \\
\text { increase) }\end{array}$ & 1.24 & 1.02 to 1.50 & 0.034 & & & \\
\hline \multicolumn{7}{|l|}{ DAS28 } \\
\hline$<3.2$ & Referent & & & & & \\
\hline 3.2 to 5.1 & 1.28 & 0.54 to 3.06 & 0.58 & & & \\
\hline$>5.1$ & 2.00 & 0.82 to 4.86 & 0.13 & & & \\
\hline \multicolumn{7}{|l|}{ Ever exposed to } \\
\hline $\begin{array}{l}\text { Conventional } \\
\text { DMARDs only }\end{array}$ & Referent & & & Referent & & \\
\hline Anti-TNF agents & 0.61 & 0.39 to 0.97 & 0.039 & 0.70 & 0.44 to 1.12 & 0.133 \\
\hline Anakinra & 1.16 & 0.47 to 2.89 & 0.75 & 1.39 & 0.56 to 3.48 & 0.480 \\
\hline
\end{tabular}

receiving conventional DMARDs. This may be due to a selection bias evoked by the screening process for malignancies following the physician's decision that a patient should receive biologic treatment. Screening for latent TB by chest $\mathrm{x}$-ray as recommended in guidelines [21] may reveal asymptomatic lung cancers and only those patients who screen negative for current malignancies will receive biologic treatment and be included in the biologics group in the RABBIT register. No such general screening occurs in patients who will receive a new DMARD therapy. Therefore the rate for malignancies in the DMARD group represents the true unselected rate that can be expected for RA patients under conventional DMARD treatment. Indeed this concept is supported by our findings that the observed number of cancer cases in the DMARD treated group $(\mathrm{n}=30)$ was equal to the expected number $(n=30.8)$, whereas the observed number in the biologics group $(n=44)$ was lower than what would have been expected based on the rates from the general population $(n=64.3)$.

In contrast to an increased risk, it is also possible that inhibition of TNF $\alpha$ has beneficial or even preventive effects regarding cancer. TNF $\alpha$ is important in all steps of cancer development, for example, initiation, promotion, and survival. Elevated levels of TNF $\alpha$ are linked to a poor prognosis and increased invasiveness in certain human cancers $[22,23]$. However, the results of first trials to treat breast or ovarian cancer with $\mathrm{TNF} \alpha$ inhibitors have been, so far, inconclusive [24,25]. The increased risk of non-Hodgkin's lymphoma in RA patients treated with biologic agents is well established [26,27] and has been shown to be strongly associated with long-term high disease activity [28] which is more likely in the history of patients subsequently treated with biologic agents. Nevertheless, in our nested case control study where we controlled for disease activity and duration we still found a higher proportion of anti-TNFa 
Table 5: Patient characteristics of cases and matched controls

\begin{tabular}{|c|c|c|c|}
\hline & $\begin{array}{l}\text { Cases } \\
\text { (with incident malignancy) }\end{array}$ & Matched controls & $\mathbf{P}$ \\
\hline N & 74 & 74 & \\
\hline \multicolumn{4}{|l|}{ Characteristics at study entry } \\
\hline Females\# $\mathrm{n}(\%)$ & $52(70.3)$ & $52(70.3)$ & n.a. \\
\hline $\mathrm{Age}^{\#}($ mean, SD) & $61.3(8.9)$ & $61.4(8.5)$ & 0.97 \\
\hline $\begin{array}{l}\text { Observation time } \text { (years) }^{\text {(median, IQR) }}\end{array}$ & $2.9(1.8,4.0)$ & $2.9(1.6,3.9)$ & 0.25 \\
\hline DAS28\# (mean, SD) & $5.6(1.0)$ & $5.7(1.0)$ & 0.31 \\
\hline \multicolumn{4}{|l|}{ Smoking status\# } \\
\hline Nonsmoker & $16(21.6)$ & $16(21.6)$ & n.a. \\
\hline Smoker n (\%) & $19(25.7)$ & $19(25.7)$ & \\
\hline Unknown status n (\%) & $39(52.7)$ & $39(52.7)$ & \\
\hline $\begin{array}{l}\text { Disease duration (years) (median, } \\
\text { IQR) }\end{array}$ & $7(3,14)$ & $9(5,16)$ & 0.22 \\
\hline $\begin{array}{l}\text { Functional status, FFbH (mean, } \\
\text { SD) }\end{array}$ & $57.1(22.3)$ & $63.2(22.6)$ & 0.058 \\
\hline \multicolumn{4}{|l|}{ Characteristics at follow-up } \\
\hline DAS28 (mean, SD) & $5.0(1.2)$ & $4.9(1.2)$ & 0.41 \\
\hline $\begin{array}{l}\text { Ever exposed to biologics } n \\
\text { (\%) }\end{array}$ & $44(59.5)$ & $45(60.8)$ & 1.0 \\
\hline $\begin{array}{l}\text { Ever exposed to anti-TNFa } \\
\text { agents \& }\end{array}$ & $44(59.5)$ & $44(59.5)$ & 1.0 \\
\hline Ever exposed to anakinra\& & $5(6.8)$ & $5(6.8)$ & 1.0 \\
\hline \multicolumn{4}{|l|}{ Among them } \\
\hline \multicolumn{4}{|l|}{ Cases with solid tumors $(n=68)$} \\
\hline Ever exposed to biologics & $39(57.4)$ & $43(63.2)$ & 0.56 \\
\hline $\begin{array}{l}\text { Ever exposed to anti-TNFa } \\
\text { agents }\end{array}$ & $39(57.4)$ & $42(61.8)$ & 0.70 \\
\hline Ever exposed to anakinra & $5(7.4)$ & $5(7.4)$ & 1.0 \\
\hline \multicolumn{4}{|l|}{$\begin{array}{l}\text { Cases with non-Hodgkin's } \\
\text { Lymphoma }(n=6)\end{array}$} \\
\hline \multicolumn{4}{|l|}{ Characteristics at study entry } \\
\hline Females\# n(\%) & $5(83.3)$ & $5(83.3)$ & n.a. \\
\hline Age\# (mean, SD) & $65.2(6.5)$ & $66.8(8.0)$ & 0.13 \\
\hline Disease duration & $5.5(4,13)$ & $7(5,11)$ & 0.53 \\
\hline $\begin{array}{l}\text { Functional status, FFbH (mean, } \\
\text { SD) }\end{array}$ & $52.8(31.4)$ & $54.2(27.5)$ & 0.90 \\
\hline DAS28\# (mean, SD) & $5.9(0.6)$ & $6.2(0.5)$ & 0.29 \\
\hline \multicolumn{4}{|l|}{ Characteristics at follow-up } \\
\hline DAS28 (mean, SD)\$ & $5.2(0.7)$ & $5.5(0.7)$ & 0.14 \\
\hline $\begin{array}{l}\text { Ever exposed to anti-TNFa } \\
\text { agents }\end{array}$ & $5(83.3)$ & $2(33.3)$ & 0.38 \\
\hline
\end{tabular}

" matching criteria (further matching criteria not shown in the table = COPD, other chronic lung disease, chronic renal disease, chronic gastrointestinal disease, chronic liver disease, and psoriasis)

\&five cases and four controls received anti-TNFa agents and anakinra (at different points in time)

\$cases = mean of DAS28 values over time points until six months prior to the cancer diagnosis, matched controls: mean of DAS28 values over time points of the corresponding case 
exposure in patients with incident non-Hodgkin's lymphomas vs matched controls. This difference was not found for solid tumors.

\section{Conclusions}

Our data add to the growing evidence of no overall increased cancer risk for patients treated with anti-TNFa agents during the first years of treatment. This does not preclude that there may be an increased risk for specific cancer types such as lymphoma or skin cancer.

Taking the limitations of the currently available evidence into account there is a need for further large-scale prospective studies investigating risk modifications for different cancer sites as well as investigating the cancer risk after long-term exposure to biologic agents above four years.

Further, this study provides first but limited evidence regarding the risk of patients with a prior malignancy treated with anti-TNF $\alpha$ agents. The finding of an insignificantly increased risk of recurrence under anti-TNF $\alpha$ treatment supports the current practice of carefully balancing treatment decisions in these patients.

\section{Abbreviations}

ACR: American College of Rheumatology; BSRBR: British Society of Rheumatology Biologics Register; Cl: confidence interval; COPD: chronic obstructive pulmonary disease; DAS28: disease activity score based on 28 joint counts; DMARDs: disease modifying anti-rheumatic drugs; FFbH: Hannover Functional Status Questionnaire (Funktionsfragebogen Hannover); HAQ: Health Assessment Questionnaire; HR: hazard ratio; IQR: interquartile range; IR: incidence rate; IRR: incidence rate ratio; MedDRA: Medical Dictionary for Regulatory Affairs; OR: odds ratio; pyrs: patient-years; RA: rheumatoid arthritis; RABBIT: (German biologics register) acronym for: rheumatoid arthritis observation of biologic therapies; RCT: randomized controlled trial; SD: standard deviation; TB: tuberculosis; TNFa: tumor necrosis factor alpha.

\section{Competing interests}

The authors declare that they have no competing interests.

\section{Authors' contributions}

AS, JL and AZ had full access to all of the data in the study and took responsibility for the integrity of the data and the accuracy of the data analysis. AZ, JL and AS determined the study concept and design. AS, GRB, BK-L and WD acquired the data. $A S, J L$ and $A Z$ analysed and interpreted the data. $A S, J L$ and $A Z$ drafted the manuscript. RR, GRB, BK-L, WD and FH critically revised the manuscript for important intellectual content and final approval. FH and $J \mathrm{~L}$ did the statistical analysis. AZ obtained the funding and supervision. AS supervised adverse events reporting, verifications and MedDRA coding. All authors gave final approval of the version to be published.

\section{Acknowledgements}

RABBIT has been supported by an unconditional, joint grant from Essex Pharma (since 2001), Wyeth pharma (since 2001), Amgen (2003 to 2008)/Biovitrum (since 2009), and Abbott (since 9/2003). Since 2007, it has also been supported by Bristol-Myers Squibb and Roche, and since 2009 by UCB. The principal investigators and their team have full academic freedom in study design and conduct, data analysis and publication of results. This is laid down in the contract with the sponsors. However, for the purposes of information all six funding companies receive each manuscript 30 days prior to submission. The authors acknowledge the invaluable contributions of all participating consultant rheumatologists and would like to thank in particular those who enrolled at least 25 patients each: Ulrich von Hinüber, MD, Hildesheim; Andreas Krause, MD, Immanuel hospital Berlin; Maria Stoyanova-Scholz, MD, Wedau Kliniken, Duisburg; Karin Babinsky, MD, Halle; Thilo Klopsch, MD, Neubrandenburg; Arnold Bussmann, MD, Geilenkirchen; Hans Peter Tony, MD, Medizinische
Poliklinik der Universität Würzburg; Katja Richter, MD, Universitätsklinikum Carl Gustav Carus Dresden; Anett Grässler, MD, Pirna; Elke Wilden, MD, Köln; Michael Hammer, MD, St. Josef-Stift Sendenhorst; Edmund Edelmann, MD, Bad Aibling; Christina Eisterhues, MD, Braunschweig; Wolfgang Ochs, MD, Bayreuth; Thomas Karger, MD, Eduardus-Krankenhaus Köln-Deutz; Michael Bäuerle, MD, Universität Erlangen, Erlangen; Herbert Kellner, MD, München; Silke Zinke, MD, Berlin; Angela Gause, MD, Elmshorn; Lothar Meier, MD, Hofheim; Karl Alliger, MD, Zwiesel; Martin Bohl-Bühler, Brandenburg; Carsten Stille, MD, Hannover; Susanna Späthling-Mestekemper, MD, and Thomas Dexel, MD, München; Harald Tremel, MD, Hamburg; Stefan Schewe, MD, Medizinische Poliklinik der Ludwig-Maximilians-Universität München; Helmut Sörensen, MD, Krankenhaus Waldfriede Berlin; Florian Schuch, MD, Erlangen; Klaus Krüger, MD, München; Andreas Teipel, MD, Leverkusen; Kirsten Karberg, MD, Berlin; Gisela Maerker-Alzer, MD, and Dorothea Pick, MD, Holzweiler; Volker Petersen, MD, Hamburg; Kerstin Weiss, MD, Lichtenstein; Werner Liman, MD, Ev. Krankenhaus Hagen-Haspe; Kurt Gräfenstein, MD, Johanniter-Krankenhaus im Fläming, Treuenbrietzen; Jochen Walter, MD, Rendsburg; Werner A. Biewer, MD, Saarbrücken; Roland Haux, MD, Berlin; Gross Lübeck; Michael Zänker, MD, Evangelisches Freikirchliches Krankenhaus Eberswalde; Gerhard Fliedner, MD, Osnabrück; Thomas Grebe, MD, Ev. Krankenhaus Kredenbach; Karin Leumann, MD, Riesa; Jörg-Andres Rump, MD, Freiburg; Joachim Gutfleisch, MD, Biberbach; Michael Schwarz-Eywill, MD, Evangelisches Krankenhaus Oldenburg; Kathrin Fischer, MD, Greifswald; Monika Antons, MD, Köln.

We also acknowledge the significant contributions to the conception of RABBIT of Matthias Schneider, MD, University of Duesseldorf, Jörn Kekow, MD, University of Magdeburg, and Peter Herzer, MD, Munich in their function as members of the advisory board. The work in the advisory board of RABBIT is honorary without any financial compensation.

The substantial contribution of Christina Bungartz, Ulrike Kamenz, and Susanna Zernicke, all employees of the German Rheumatism Research Center, Berlin, in the study monitoring and support of the data analyses is gratefully recognized.

\section{Author Details}

'German Rheumatism Research Centre Berlin, a Leibniz institute, Charitéplatz 1, 10117 Berlin, Germany, 2Irisweg 5, 40489 Duesseldorf, Germany, ${ }^{3}$ Department of Rheumatology and Clinical Immunology, Charité-University Medicine Berlin, Charitéplatz 1, 10117 Berlin, Germany, ${ }^{4}$ Stresemannallee 3, 60596 Frankfurt, Germany and ${ }^{5}$ Bahnhofsallee 3-4, 31134 Hildesheim, Germany

Received: 28 July 2009 Revisions Requested: 21 August 2009

Revised: 30 November 2009 Accepted: 8 January 2010

Published: 8 January 2010

\section{References}

1. Carswell EA, Old $\sqcup$, Kassel RL, Green S, Fiore N, Williamson B: An endotoxin-induced serum factor that causes necrosis of tumors. Proc Natl Acad Sci USA 1975, 72:3666-3670.

2. Perkins ND: NF-kappaB: tumor promoter or suppressor? Trends Cell Biol 2004, 14:64-69.

3. Bongartz T, Sutton AJ, Sweeting MJ, Buchan I, Matteson EL, Montori V: Anti-TNF antibody therapy in rheumatoid arthritis and the risk of serious infections and malignancies: systematic review and metaanalysis of rare harmful effects in randomized controlled trials. JAMA 2006, 295:2275-2285.

4. Bongartz T, Warren FC, Mines D, Matteson EL, Abrams KR, Sutton AJ: Etanercept therapy in rheumatoid arthritis and the risk of malignancies. A systematic review and individual patient data metaanalysis of Randomized Controlled Trials. Ann Rheum Dis 2008, 68:1177-1183.

5. Watson KD, Dixon WGHK, Lunt M, Symmons DP, Silman AJ, BSRBR Control Centre Consourtium: Influence of anti-TNF therapy and previous malignancy on cancer incidence in patients with rheumatoid arthritis (RA): Results from the BSR Biologics Register. Ann Rheum Dis 2006, 65:512.

6. Dixon WG, Watson KD, Lunt M, BSRBR Control Centre Consortium, Hyrich $\mathrm{KL}$, Symmons DPM: The influence of anti-TNF therapy upon cancer incidence in patients with rheumatoid arthritis (RA) who have had prior malignancy: Results from the BSRBR. Arthritis Rheum 2008, 58:S638-5639. 
7. Deutsche Gesellschaft für Rheumatologie: [Recommendations of the German Society of Rheumatology for therapy with tumor necrosis factor inhibitors. Pharmacotherapy Committee of the German Society of Rheumatology]. [http://dgrh.de/fileadmin/media/ Qualitaetssicherung/Therapie-Empfehlungen/TNF-Blocker 06.pdf). (last access 2/11/2009)

8. Zink A, Listing J, Kary S, Ramlau P, Stoyanova-Scholz M, Babinsky K, von Hinueber U, Gromnica-Ihle E, Wassenberg S, Antoni C, Herzer P, Kekow J, Schneider M, Rau R: Treatment continuation in patients receiving biological agents or conventional DMARD therapy. Ann Rheum Dis 2005, 64:1274-1279.

9. Strangfeld A, Listing J, Herzer P, Liebhaber A, Rockwitz K, Richter C, Zink A: Risk of herpes zoster in patients with rheumatoid arthritis treated with anti-TNF (alpha) agents. JAMA 2009, 301:737-744.

10. International Conference on Harmonisation: Clinical Safety Data Mangement: Definitions and standards for expedited reporting. 1995 [http://www.emea.europa.eu/pdfs/human/ich/037795en.pdf]. (last access at 16/06/2009)

11. MedDRA Maintenance and Support Services Organization 2007 [http:/ /www.meddramsso.com]. (last access 16/06/09)

12. Lautenschlaeger J, Mau W, Kohlmann T, Raspe HH, Struve F, Bruckle W, Zeidler H: [Comparative evaluation of a German version of the Health Assessment Questionnaire and the Hannover Functional Capacity Questionnaire]. ZRheumatol 1997, 56:144-155.

13. Robert-Koch-Institut (publisher): Krebsneuerkrankungen in Deutschland (Cancer incidence in Germany). 2009 [http://www.rki.de] (last access 07.06.2009)

14. Jones M, Symmons D, Finn J, Wolfe F: Does exposure to immunosuppressive therapy increase the 10 year malignancy and mortality risks in rheumatoid arthritis? A matched cohort study. Br J Rheumatol 1996, 35:738-745.

15. Dempster AP, Laird NM, Rubin DB: Maximum Likelihood from Incomplete Data Via Em Algorithm. Journal of the Royal Statistical Society Series B-Methodological 1977, 39:1-38.

16. Therneau TM, Grambsch PM: Modelling Survival Data. New York: Springer; 2000.

17. Zink A, Strangfeld A, Schneider M, Herzer P, Hierse F, Stoyanova-Scholz M, Wassenberg S, Kapelle A, Listing J: Effectiveness of tumor necrosis factor inhibitors in rheumatoid arthritis in an observational cohort study: comparison of patients according to their eligibility for major randomized clinical trials. Arthritis Rheum 2006, 54:3399-3407.

18. Askling J, Fored CM, Brandt L, Baecklund E, Bertilsson L, Feltelius N, Cöster L, Geborek P, Jacobsson LT, Lindblad S, Lysholm J, Rantapää-Dahlqvist S, Saxne T, Klareskog L: Risks of solid cancers in patients with rheumatoid arthritis and after treatment with tumour necrosis factor antagonists. Ann Rheum Dis 2005, 64:1421-1426.

19. Wolfe F, Michaud K: Biologic treatment of rheumatoid arthritis and the risk of malignancy - Analyses from a large US observational study. Arthritis Rheum 2007, 56:2886-2895.

20. Dixon W, Silman A: Is there an association between anti-TNF monoclonal antibody therapy in rheumatoid arthritis and risk of malignancy and serious infection? Commentary on the meta-analysis by Bongartz et al. Arthritis Res Ther 2006, 8:111.

21. Ledingham J, Wilkinson C, Deighton C: British Thoracic Society (BTS) recommendations for assessing risk and managing tuberculosis in patients due to start anti-TNF-\{alpha\} treatments. Rheumatology (Oxford) 2005, 44:1205-1206.

22. Sethi G, Sung B, Aggarwal BB: TNF: a master switch for inflammation to cancer. Front Biosci 2008, 13:5094-5107.

23. Balkwill F: TNF-alpha in promotion and progression of cancer. Cancer Metastasis Rev 2006, 25:409-416.

24. Madhusudan S, Muthuramalingam SR, Braybrooke JP, Wilner S, Kaur K, Han C, Hoare S, Balkwill F, Ganesan TS: Study of etanercept, a tumor necrosis factor-alpha inhibitor, in recurrent ovarian cancer. J Clin Oncol 2005, 23:5950-5959.

25. Madhusudan S, Foster M, Muthuramalingam SR, Braybrooke JP, Wilner S, Kaur K, Han C, Hoare S, Balkwill F, Talbot DC, Ganesan TS, Harris AL: A phase II study of etanercept (Enbrel), a tumor necrosis factor alpha inhibitor in patients with metastatic breast cancer. Clin Cancer Res 2004, 10:6528-6534.
26. Baecklund E, Ekbom A, Sparen P, Feltelius N, Klareskog L: Disease activity and risk of lymphoma in patients with rheumatoid arthritis: nested case-control study. BMJ 1998, 317:180-181.

27. Prior P, Symmons DP, Hawkins CF, Scott DL, Brown R: Cancer morbidity in rheumatoid arthritis. Ann Rheum Dis 1984, 43:128-131.

28. Baecklund E, lliadou A, Askling J, Ekbom A, Backlin C, Granath F, Catrina Al, Rosenquist R, Feltelius N, Sundström C, Klareskog L: Association of chronic inflammation, not its treatment, with increased lymphoma risk in rheumatoid arthritis. Arthritis Rheum 2006, 54:692-701.

doi: 10.1186/ar2904

Cite this article as: Strangfeld et al., Risk of incident or recurrent malignancies among patients with rheumatoid arthritis exposed to biologic therapy in the German biologics register RABBIT Arthritis Research \& Therapy 2010, 12:R5 